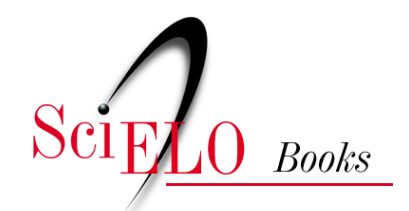

\title{
Magistério e literatura em periódicos alagoanos da década de 1880 \\ as composições poéticas de Alcina Leite e Maria Lucia Romariz
}

\author{
Maria das Graças de Loiola Madeira
}

\section{SciELO Books / SciELO Livros / SciELO Libros}

MADEIRA, M.G.L. Magistério e literatura em periódicos alagoanos da década de 1880: as composições poéticas de Alcina Leite e Maria Lucia Romariz. In: SILVA, E.O.C., SANTOS, I.G. and ALBUQUERQUE, S.L., orgs. A história da educação em manuscritos, periódicos e compêndios do $X I X$ e $X X$ [online]. Rio de Janeiro: EdUERJ, 2018, pp. 63-78. ISBN 978-85-7511-483-4.

https://doi.org/10.7476/9788575114834.0005.

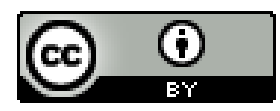

All the contents of this work, except where otherwise noted, is licensed under a Creative Commons Attribution 4.0 International license.

Todo o conteúdo deste trabalho, exceto quando houver ressalva, é publicado sob a licença Creative Commons Atribição $\underline{4.0}$.

Todo el contenido de esta obra, excepto donde se indique lo contrario, está bajo licencia de la licencia $\underline{\text { Creative Commons }}$ $\underline{\text { Reconocimento 4.0. }}$. 


\title{
MAGISTÉRIO E LITERATURA EM PERIÓDICOS ALAGOANOS DA DÉCADA DE 1880
}

\author{
As composições poéticas de Alcina Leite \\ e Maria Lucia Romariz
}

Maria das Graças de Loiola Madeira

\section{Introdução}

Em 1889, a professora primária alagoana Alcina Carolina Leite (1854-1939) publicou em Maceió a primeira e única obra de poesia com o título Campesinas, com versos já circulados em jornais de Maceió, Recife e Laranjeiras (SE). No ano anterior, a colega conterrânea, e também professora, Maria Lucia Romariz (186319171), efetivava um projeto ambicioso para uma jovem viúva: pôr em circulação um almanaque destinado a publicar e intercambiar as produções literárias de mulheres brasileiras e portuguesas da década de 1880. Tratava-se do Almanach Litterario Alagoano das Senhoras (1888-89). Editado em Maceió, o periódico recebia a colaboração de nomes com circulação nacional, entre as quais, a baiana Ana Autran, a pernambucana Francisca Izidora, as cearenses Francisca Clotilde e Alba Valdez, a gaúcha Cândida Fortese Se-

1 O ano de 1917 é apenas indicação baseada na consulta aos periódicos. A data exata da morte de Maria Lúcia ainda é desconhecida. 
nhorinha Chaves, a paraibana Anna Ribeiro e as sergipanas Maria Cândida Ribeiro e Maria Minervina de Menezes. As composições poéticas de Alcina Leite e Maria Lúcia tiveram na imprensa periódica seu lugar de circulação, em jornais como Gutenberg, O Orbe, livro e almanaques.

A partir das fontes apresentadas, este texto pretende refletir acerca das relações entre magistério, literatura e imprensa periódica da década de 1880, e a respectiva colaboração de tal produção na conformação de valores morais e sociais que constituíram a sociedade brasileira naquele final de século.

As duas jovens professoras protagonizaram o lugar do feminino numa época de vigilância e dominação da publicação masculina ou dos representantes da intelligentsia brasileira. Desse universo, as mulheres eram geralmente conduzidas com prescrições para qualquer atividade que exercessem em público, em particular, a literatura e o magistério. De algum modo, mulheres como Alcina Leite e Maria Lúcia foram pioneiras em colaborar para um lugar social a partir do qual a figura feminina brasileira se beneficiou ao longo do século XX.

A formação culta e refinada de mulheres como as jovens alagoanas era requerida pela elite nacional para a formação de suas filhas, com o propósito de projetá-las para um lugar socialmente diferenciado dos seus contextos. Essa projeção se daria pela circulação de ideias em impressos e nos demais espaços sociais, inclusive na escola, com a modelagem de mentes e corpos pela ação docente. Nesses termos, Alcina Leite e Maria Lúcia não se associavam ao conceito de intelectuais, com "prática de expor e divulgar ideais e credos políticos" (Boto, 2003, pp. 283-4), mas impulsionaram uma luta quase invisível que representava a saída do confinamento do lar para ganhar um lugar público e de prestígio social (Schueler, 2008).

Inicialmente, este texto discute as relações entre imprensa e literatura no final do Império e seu papel na formação de valores necessários à nação brasileira, que se pretendia republicana. A pro- 
dução literária publicada por professores em periódicos torna-se fonte privilegiada para quem se debruça sobre o tema, tanto pelo uso frequente por parte daqueles que não podiam custear edições de livros quanto pelo período de profissionalização do ofício (Andrade, 2015). Por ser também um lugar de conformação social, a imprensa tornava-se porta-voz do projeto político nacional republicano, considerando a exitosa relação entre palavra e poder exercitada nos jornais de larga circulação, nos periódicos e almanaques especializados (Neves, 2009).

$\mathrm{Na}$ sequência, o texto indaga sobre as relações entre imprensa, magistério e literatura nas composições de Alcina Leite e Maria Lucia, discutindo os modelos de formação para jovens que prosseguiram tanto no universo literário quanto na docência.

\section{A literatura alagoana em periódicos da década de 1880}

A relação entre imprensa e literatura, na segunda metade do século XIX, tornava públicos os valores que constituiriam a nação brasileira, um deles, acerca dos incipientes sinais de uma sociedade democrática que passavam pelo universo das letras. Os intelectuais, em particular os literatos, cumpriram um papel importante naquele momento de fortes convicções político-republicanas, ao tempo em que se profissionalizam em suas especialidades: poemas, contos e romances (Andrade, 2015). Machado de Assis se colocaria a respeito, ao comparar o jornal a um lugar de debate, onde se veiculava diariamente a palavra impressa acalorada (Assis, 1859 apud Andrade, 2015).

Deve-se considerar, entretanto, que o público para o qual se destinavam os jornais era apenas uma pequena parcela da população. E ter lugar na imprensa significava também fazer parte de uma pequena elite intelectual, econômica e política, que facilitava as aproximações com quem detinha o poder, inclusive, de fazer cir- 
cular os periódicos nas capitais provinciais. A circulação da escrita literária tinha também o propósito de render homenagens àqueles da simpatia dos proprietários dos jornais. Isso, portanto, colocava as letras sob a tutela da troca de favores, desde as relações familiares e políticas até as de ordem econômica. Uma vez atendidas as regras tácitas estabelecidas para o ingresso, logo os jornalistas e literatos galgariam ascensão na própria imprensa, no parlamento, nos cargos públicos ou em qualquer outra função. Não por acaso, Andrade (2015) ressalta que a literatura veiculada nos jornais tornava-se um instrumento de formação moral, a exemplo dos folhetins publicados nos rodapés dos jornais, além das seções de poemas, crônicas e contos, que depois se converteriam em outros veículos impressos: revistas especializadas, livros e almanaques. $\mathrm{O}$ espaço reservado à literatura, nesse veículo de informação, seria uma sinalização da imprensa como lugar de exercício de liberdade: “[...] a imprensa periódica pretendia também marcar e ordenar uma cena pública que passava por transformações no âmbito das relações de poder e de suas dimensões culturais e que dizia respeito a amplos setores da hierarquia social em suas relações políticas e sociais" (Neves, 2009, p. 163).

Foi nesse universo intelectual que Alcina Leite e Maria Lucia exerceram os ofícios de literata e professora. Ambas tinham vínculos parentais com pessoas já inseridas no universo da palavra impressa oitocentista. O bacharel e professor primário Antonio Leite Pindahiba, irmão de Alcina Leite, mantinha frequente publicação de composições literárias em jornais de Maceió: O Liberal, Diário da Manhã e Gutenberg. Quando publicou, em 1880, o livro Iris da escola - um pequeno manual de metodologia de alfabetização infantil -, ele recebeu da imprensa notas de incentivo sobre a qua- 
lidade do texto, além de anúncios de venda no jornal $O$ Liberal . É provável que os vínculos do irmão com a imprensa tenham de algum modo facilitado o convite pelo jornal Gutenberg (1881) para que Alcina Leite se tornasse colaboradora da seção "Litteratura", sobre a qual abordaremos à frente.

Quanto à Maria Lúcia, seu esposo Antonio de Almeida Romariz era poeta e professor de francês e latim em Maceió, tendo sido suas composições poéticas publicadas no Gutenberg. Antes de falecer, em 1883, ele reuniu o conjunto de seus escritos literários, circulados na imprensa, e editou a obra Auras matutinas. Em que pese a morte prematura, aos trintas anos, o nome de Antonio Romariz serviu de apoio a Maria Lúcia quando ela fundou, em 1883, o Atheneu Alagoano, um colégio feminino para jovens maceioenses. Particularmente, os redatores do Gutenberg e de OOrbe se diziam sensibilizados com a situação financeira da jovem viúva e, com esses argumentos, passaram a apoiar o seu projeto pedagógico. Em 1888, com o nome já conhecido na imprensa, a proprietária do Atheneu Alagoano pôs em circulação o Almanack Litterario Alagoano das Senhoras ${ }^{3}$. Em decorrência dessas inserções, Alcina Leite e Maria Lucia tiveram seas poemas publicados no Almanaque luso-brasileiro, editado em Lisboa. O conto "Primeira nuvem", de Maria Lucia, foi dedicado ao "festejado poeta pernambucano J.

${ }^{2}$ Em 16 de julho de 1880, o jornal O Liberal divulgava: "Iris da Escola: novo methodo para aprender a ler a letra redonda e a manuscripta em 30 lições, pelo professor Antonio Francisco Leite Pindahiba. Obra organizada sob os novos preceitos do ensino primário ultimamente adoptados a compreensão das crianças" (ano XIII, n. 159, p. 4)

${ }^{3}$ Maria Lucia havia concluído o Liceu Provincial, um feito para poucas mulheres do Brasil Império, considerando que a escola primária e o curso normal eram os únicos caminhos comumente destinados àquelas interessadas em galgar espaços no universo das letras. Anna Sampaio, irmã de Lucia, foi a primeira mulher alagoana a finalizar um curso de Direito (1893). 
Duarte Filho" e publicado na edição de 1887 (p. 132). No mesmo periódico, Alcina Leite publicaria "Sensictiva" .

Como se pode observar, o ingresso das duas professoras e literatas na imprensa local teve a decisiva influência das relações familiares no acolhimento de suas produções literárias. Não chega a ser novidade tal discussão, uma vez que a imprensa era um espaço social tanto quanto outro no Brasil Império, onde prevaleciam às trocas, as relações parentais e a convivência com grupos de prestígio em suas respectivas províncias, para assim também galgarem postos socialmente prestigiados.

\section{A docência e a poesia de Alcina Leite}

Nascida em Atalaia, no ano de 1854, Alcina Carolina Leite Pindahíba formou-se pela Escola Normal de Alagoas, em data ignorada. Em 23 de outubro de $1873^{5}$, aos 19 anos, ela tornou-se professora pública provincial, de uma cadeira do sexo feminino em Coqueiro Seco. Em 1892, Alcina foi nomeada professora do sexo masculino ${ }^{6}$ de $2 .^{\circ}$ grau da Escola Modelo de Maceió, experiência da qual ela se recordou um ano antes de falecer, em correspondência de 09 de novembro de 19387.

No ano da proclamação da República brasileira, a professora reuniu o conjunto de suas poemas e publicou Campesinas, impres-

4 A data exata do periódico não foi localizada. O apoio dessa informação encontra-se em nota do jornal maceioense Gutenberg, de 20 de fevereiro de 1881.

5 Conforme relatório do Governo da Província das Alagoas para o ano de 1882, a turma assumida teve matrícula de 33, com frequência de 20 alunas.

6 Cf. Jornal Cruzeiro do Norte, Maceió, 23 de dezembro 1892. No Regulamento da Escola, aprovado desde 04 de outubro de 1894, consta que ela "obedecia a um regime especial por integrar a Escola Normal responsável pelo ensino pratico. Dividia-se em très graus e era dirigida por seis professores, dividida igualmente pelo sexo" (Relatório dos Presidentes da Provincia das Alagoas, 15 de abril de 1901, p. 09).

7 Carta localizada no acervo do Instituto Histórico e Geográfico de Alagoas. 
so em Maceió, na Tipografia de Amintas Mendonça, com 126 páginas. O título alude à vida rural em Coqueiro Seco, cidade na qual permaneceu até seus últimos dias. Os versos já haviam sido publicados entre 1877 e 1889, em periódicos locais, entre os quais, Gutenberg, A Escola, Almanack Litterario Alagoano das Senhoras, fundado por Maria Lúcia, além de publicações na imprensa fora de Alagoas, Recife e Laranjeiras (SE). Em Novo Almanach de Lembranças Luso-Brazileiro, Alcina Leite publicaria versos sob o pseudônimo de "Sensictiva". O nome da professora e escritora surgia também associado à fundação do Almanack Literário Alagoano para 1900, quando o cronista Luis Lavenère o levou a público, em 1904. Antes da edição de Campesinas, Alcina Leite colaborou de forma vigorosa no jornal Gutenberg, inaugurando a seção "Litteratura”, em 20 de fevereiro de 1881. Ao apresentá-la, o redator do periódico referiu-se a ela como escritora e professora pública de Coqueiro Seco:

Stabat Mater ${ }^{8}$, sob este título abrimos hoje espaço em nosso jornal a uma sublime poesia.

Alcina Leite, meretissima professora publica de Coqueiro Seco.

Tal modesta quão talentosa, a nossa jovem patrícia não vem estrear nas humildes columnas do Gutemberg; em outras jornaes desta capital, e nas paginas do Almanak Luzo-Brasileiro, sob o pseudônimo - Sensictiva - já tem a exma. d. Alcina Leite se revelado poetisa inspirada e culta distincta das letras. Saudamos enthusiasticos a illustrada preceptora alagoana, pedimos-lhe digne-se honrar-nos sempre com as

8 O referido poema integra a obra Campesinas (1889, p. 20), e trata da passagem bíblica, especificamente, o sofrimento de Maria diante do filho crucificado. Portanto, a frase em latim pode ser traduzida como "Tristeza materna”. 
mimosas produções de sua intelligencia brilhante (Gutenberg, 20 fev. 1881).

Em Recife, a autora de Campesinas publicou em o Lyrio, e em Laranjeiras (SE) o poema "O joaseiro". Com versos de feitura simples, aliada à melancolia e à tristeza, Alcina Leite transformava em poesia a solidão, o amor e a vida mortificada, de forma que seguia uma tradição poética do Oitocentos, ou seja, um lirismo que tinha um apelo quase confessional. No prefácio da obra, o tom intimista do poema anuncia uma vida de sacrifícios e mortificação, mas também as alegrias de quem vivia no campo, próximo à natureza: "Pobre visionaria, fiz da poesia a minha fada consoladora, a minha irmã d'alma, a doce amiga a quem confiei todos os meos segredos: não mais. Como toda gente, eu comprehendo as naturaes alegrias da mocidade, - turbulenta de rapazes, loquacidade de meninas, risadas crystallinas da infância”. Em meio aos versos estão algumas referências de nomes da literatura brasileira que indicam as leituras da ilustre professora, a exemplo de Gonçalves Dias, Laurindo Rebello, Thomaz Ribeiro, Casemiro de Abreu, Fagundes Varella e José de Alencar. A Julio Verne, ela dedica atenção em Alice (impressóes de leitura) (p. 41). O teor dos poemas e dos contos da professora alagoana pode nos indicar o perfil do magistério ou o viés confessional e romântico, quando passagens bíblicas são referenciadas, como a de Sta. Theresinha de Jesus e de Sto. Antonio de Lisboa, mas também poemas em homenagens, felicitações e dedicatórias a parentes e amigos, por ocasião de nascimentos, casamentos, aniversários e mortes.

Alcina Leite dedicou, em Campesinas, alguns de seus versos à colega de ofício e conterrânea, Maria Lucia, numa época na qual a autora do Almanaque das Senhoras era viúva. Em "Desilusões - á minha amiga d. Maria Lucia” (p. 74), Alcina Leite se apoia em passagem de Queiroz Ribeiro para homenagear a colega: "E a gente fica, entre abismado e louco, cheio de espanto e de tristeza e dó, 
ao ver que o pó era aquelle oiro há pouco, e ao ver que o oiro era somente ... pó”.

Raras vezes o universo escolar era transformado em poesia, o que pode soar estranho para alguém como Alcina, reconhecida como professora pública e próxima à infância nas aulas da escola primária feminina em Coqueiro Seco. Exceção encontra-se em "A primeira lição", em que a menina Laura recebe um presente: “Trouxe-lhe o pae, um dia, um livro lindo, um 'Alphabeto d'Ouro', e o anjo, rindo: 'Ensina-me a lição!' pede ao papá. Volve após n’um transporte de ventura. E diz à mãe, que chora de ternura: 'Olha, mamã, - eu já conheço o 'A'” (Coqueiro Seco, 27 de dezembro de 1888, p. 67).

Os dois ofícios, de fato, pareciam apartados nos impressos. $\mathrm{O}$ que teria Alcina Leite se apropriado da literatura para o magistério? Provavelmente não se terá facilmente tal resposta, mas, entre suas liras, há um perfil de modelos femininos destinados à contenção da dor e do sofrimento, em nome da família e de seu lugar socialmente demarcado. Portanto, as composições provavelmente serviam para exposição tanto de quem se encontrava em espaços socialmente demarcados e vigiados quanto de portadoras de valores morais na imprensa e na escola.

Aos anos de docência se seguia também o vínculo com o Instituto dos Professores Primários, que funcionava desde 18 de outubro de 1886, cujo propósito era auxiliar na formação dos professores e ofertar cursos e conferências públicas. Dois periódicos colaboravam: O Magistério e o 15 de Outubro. O irmão de Alcina, Antonio Leite', era um dos nomes da instituição, juntamente com

9 Antonio F. Leite Pindahyba era professor de escola pública primária em Atalaia, desde 1874. Ao publicar a obra Iris da Escola, ele pretendia que fosse adotada pela província para circular nas escolas primárias. Fato que não ocorreu: "Reprovado pela congregação do Liceu O Iris da Escola, nem mesmo o seu 
Francisco Domingos da Silva, diretor do IPP ${ }^{10}$. De propaganda abolicionista, o Instituto aproveitou os festejos dos 170 anos da Primeira Lei de Instrução Publica, de 15 de outubro de 1827, para realizar um ato simbólico: Alcina Leite, o irmão e a cunhada, também professora pública, alforriaram uma escrava de nome Monica, com 29 anos, para a qual foi entregue, na ocasião, a carta que a tornava livre ${ }^{11}$. O sentido de liberdade atribuído ao aniversário da lei de 15 de outubro de 1827, com a libertação da escrava, simbolizava a luta do IPP também para pôr fim a dois estigmas do Brasil-Império: o analfabetismo e a escravidão, ambos associados a um sentimento de vergonha nacional que atrasava a modernidade do país.

O falecimento de Alcina Leite provavelmente ocorreu em 1939, quando ainda publicava versos de conteúdo religioso no jornal maceioense Gazeta de Alagoas. Numa carta manuscrita enviada de Coqueiro Seco, em 9 de novembro de 1938, a autora de Campesinas se dirige ao colega Aminadab Valente: "O Sr. só me vê através d'aqueles versinhos a N. Senhora”. Além de queixar-se de seu frágil estado de saúde, responde à solicitação de elaborar um escrito sobre suas memórias "O seu gesto pedindo que lhe mande cousa da minha meninice para publicar não me anima, pois nasce da sympatia do Sr. e de suas irmãs pelas minhas tão simples composiçaozinhas, mas é que tudo agora já me cansa, quase não posso nem copiar".

autor, que é professor publico, o podia admitir em sala de aula" (O Orbe, 2 de julho de 1882, ano IV, n. 71, p. 1).

10 A professora pública Julia de Carvalho colaborava intensamente como IPP. Em 1888, O Magistério anuncia seu empreendimento na publicação de um Compêndio de Arithmética elementar. (Cf. O Magistério - órgão do Instituto dos Professores Primários - Revista Pedagógica, Scientifica, Litteraria e Noticiosa, ano II, Maceió, 15 fev. 1888).

11 Cf. O periódico 15 de Outubro, de 1886. Maceió, n. único, Comemorativo da Sessão Magna do Instituto dos Professores Primários das Alagoas, p. 4. 
Em tom de despedida, finaliza: "Confesso que já tive a lembrança de despedir-me das pessoas de minha amizade, quando me fosse possível ir a Maceió, e necessariamente teria de ir à casa do senhor". É cativante constatar o apego de Alcina Leite a Coqueiro Seco, pequena cidade próxima a Maceió, que, desde o ingresso no magistério e na literatura, não desejou deslocar-se para a capital, onde tantas pretendiam trabalhar e residir ${ }^{12}$.

\section{Maria Lucia: do Atheneu ao Almanack Litterario}

Colega de ofício e amiga de Alcina Leite, a educadora e escritora Maria Lúcia Romariz ${ }^{13}$ nasceu em Palmeira dos Índios (AL), em 13 de abril de 1863. Raras publicações se referem a ela, com exceção de algumas informações biobibliográficas de Izabel Brandão (2004): "Após terminar com distinção o curso do Liceu de Maceió, ela tentou matricular-se em uma das faculdades do país, sem sucesso" (p. 239). No volume 5 do Diccionario do baiano Augusto Victorino Sacramento Blake (1882) trata que, aos vinte anos, em fevereiro de 1883, o esposo Antonio de Almeida Romariz veio a falecer, fato que a deixou desprovida de meios para sobreviver, e a fundação do Atheneu se deu, provavelmente, por tal condição.

Da mesma forma que Alcina Leite, ela apareceu na imprensa na década de 1880, tendo seu nome relacionado ao magistério e à fundação de periódicos literários. Em 2 de julho de 1883, Maria Lúcia inaugurava o colégio Atheneu Alagoano, destinado ao ensino primário e secundário para meninas e jovens maceioenses.

12 Uma biografia completa de Alcina foi escrita pelo poeta e romancista alagoano Rodolpho Alves de Faria (1871-99), ainda ignorada (Barros, 2005).

13 Maria Lucia assinava, inicialmente, com o sobrenome do esposo falecido em fevereiro de 1883, Antônio de Almeida Romariz. Em novembro de 1889, ela passou a assinar Maria Lucia Duarte, em virtude do matrimônio com João Francisco Duarte. 
Concomitante à docência, a professora e literata investiu no universo literário quando fundou A Revista Alagoana (1887), em parceria com Rita Mendonça Barros Correia. No ano seguinte, foi a vez do Almanack Litterario Alagoano das Senhoras, destinado a divulgar a literatura feminina brasileira, com algumas inserções de escritores portugueses. Seu nome também recebeu aceitação em publicações de Lisboa, com a crônica dedicada ao poeta pernambucano J. Duarte Filho, "A primeira nuvem”, no Novo Almanch de Lembranças Luso-brasileira (1888, pp. 132-6). Com o mesmo tom melancólico de Alcina Leite, Maria Lucia expôs um perfil esperado de uma figura feminina do século XIX, qual seja, naturalmente inclinada ao sofrimento, à solidão, à resignação e ao abandono: "Não te illudas, pois; segue o teu caminho, deixa-me estacionar nas minhas trevas..." (Duarte Filho, 1888).

O formato do periódico português Novo Almanch de Lembranças Luso-brasileira deve tê-la inspirado a fundar em Maceió, no mesmo ano, o já mencionado Almanack Litterario Alagoano das Senhoras $(1888)^{14}$. No periódico, ela conseguiu reunir alguns nomes da literatura feminina brasileira e portuguesa, desde a escrita literária da própria Alcina Leite, à da jovem alagoana Maria Carolina Guerra Jucá, senhoras de várias províncias brasileiras, além de escritores portugueses, como Alice Moderno, João de Deus e Joaquim Pestana. No primeiro número do Almanack, Maria Lúcia publicou o poema "Saudade", no qual ainda lamentava a morte do esposo, ocorrida em 1883: "Longe d'aqui, bem distante, onde a estrella além brilhou... Foi-se o anjo que na vida Mil venturas me offertou" (p. 39).

Quanto à docência, o nome de Maria Lucia se vinculava ao ensino particular, tanto na condição de professora e proprietária de

14 Os dois exemplares de 1888 e 1889 , do referido periódico, encontram-se no acervo do IHGAL, contendo cada um mais de 150 páginas. 
um colégio para o público feminino quanto em outras instituições e em domicílio. Nos exemplares do Almanack de sua propriedade de 1888 e 1889, foram publicados anúncios nos quais ela oferecia os serviços de professora particular de Português, Geografia e Aritmética. Seu nome também se associava ao magistério particular em outros periódicos locais, entre os quais, o Almanack do Estado de Alagoas, para o ano de 1891, e o jornal A Fé Católica, em 13 de janeiro de 1906, do Collegio SS. Sacramento, onde ela foi professora de Português. A data de seu falecimento é desconhecida, mas, até maio de 1917, Maria Lúcia era mencionada em notas dos jornais de Maceión ${ }^{15}$.

Ao fundar o colégio, de nome Atheneu Alagoano, a autora do Almanack das Senhoras pretendia ofertar às jovens alagoanas a possibilidade de realizar um sonho seu interrompido: um curso superior. Tanto que uma das propostas do colégio era ministrar o ensino secundário com o intuito de preparar jovens para os cursos superiores do Império. Consta nos estatutos do colégio que se tratava de

[...] uma instituição particular de educação domestica e social e de instrução primaria e secundaria para o sexo feminino. [...] franqueará suas portas as senhoras que quizerem se habilitar nas matérias do Curso Normal para o magistério público primário, e às que pretenderem estudar os preparatórios exigidos nas Faculdades do Império (O Orbe, 3 jul. 1883).

Era, de fato, uma proposta ousada na província de Alagoas, em razão de os demais colégios femininos ofertarem apenas as primeiras letras e as prendas domésticas. Com essa iniciativa, a edu-

15 Em 12 de maio de 1896, o Gutenberg veiculou algumas notas sobre Maria Lucia na Câmara dos Deputados do Estado de Alagoas. Não se sabe ao certo se ela ocupava algum cargo naquela casa legislativa. 
cadora e literata pretendia elevar a condição da mulher à cultura letrada. Assim, consta no Art. 7. :

O Atheneu ofertará dois cursos: [...] um contendo as materias do curso normal, que são Portuguez, Arithmetica, Geographia, História do Brasil, Pedagogia, Chatecismo, Desenho Linear, para o magistério do sexo feminino, musica vocal, Piano e Dansa; [...] Outro secundário que compreende as Liguas Portugueza, Franceza e Ingleza, a Algebra, Geometria, História Universal, Desenho de paysagem, Calligraphia, Escripturação mercantil, e noções de sciencias naturaes, incluindo physica, chimica, botânica, zoologia, higiene, ensino de cousas, \&c ( O Orbe, 3 jul. 1883).

No século XX, a atividade de escritora e professora de Maria Lucia foi suplantada pelo papel de mãe e esposa, com práticas vinculadas à caridade cristã. Mas, sua filha Anna Sampaio Duarte tornou-se professora particular do Prytaneu Alagoano, por volta de 191716, ensinando artes e letras com Rita de Souza Abreu, o nome de batismo de Rosália Sandoval, professora alagoana, que teve uma escrita literária vigorosa até meados do século XX.

\section{Considerações finais}

Dado o limite deste texto, ele se coloca como os primeiros indícios de um trabalho de investigação entre literatura, magistério e imprensa no Brasil-Império. Tantas indagações nos ocorreram, particularmente, como o universo escolar se relacionava com a literatura, considerando o ofício das duas professoras? Alguns pontos podem ser conclusivos, a exemplo dos versos com apelo confes-

${ }^{16}$ Cf. Diario do Povo, 2 fev. 1917. 
sional, realçando a dor e o sofrimento femininos. Tal indicação põe o papel dessas mulheres no ordenamento da "cena pública", como nos adverte Neves (2009) sobre o alinhamento nas relações de poder nas mais variadas esferas sociais do Oitocentos.

Embora os vínculos parentais tenham sido decisivos para a inserção de ambas na imprensa periódica, as trajetórias de Maria Lucia e Alcina Leite representaram a expressão de um protagonismo no magistério primário, para o qual a escrita literária funcionou como proteção dos estigmas da sociedade patriarcal, pois ganharam poder de expressão pública, se comparada com a grande parcela de decentes ausentes desses espaços da palavra impressa. Os versos contidos, que anunciavam uma vida silenciada e subjugada à figura masculina, não condiziam com o fato de terem insurgido como figuras ímpares naquele cenário de relações profundamente hierarquizadas.

\section{Referências}

ANDRADE, Debora E. In ENGI, M. G. et al. (orgs.). Os intelectuais e a imprensa. Rio de Janeiro: Mauad X: Faperj, 2015, pp. 13-47.

BARROS, Francisco Reinaldo A. ABC das Alagoas: dicionário biobibliográfico, histórico e geográfico de Alagoas. Brasília: Senado Federal, 2005.

BLAKE, Augusto Victoriano Alves Sacramento. Diccionario Bibliografico Brazileiro. Rio de Janeiro: Typ. Nacional, 1882.

BOTO, Carlota. "O professor primário português como intelectual: Eu ensino, logo existo”. Revista da História das Ideias, v. 24, pp. 85-134, Faculdade de Letras de Coimbra, 2003.

BRANDAO, I. F. O. "Maria Lúcia Duarte". In MUZART, Zahidé Lupinacci (org.). Escritoras brasileiras do século XIX. 1 ed. Florianópolis: Mulheres/Sta. Cruz do Sul: Edunisc, 2004, v. II, pp. 239-46. 
LAVENERE, Luis. Almanack Alagoano das Senhoras: litterario, histórico e estatístico para 1904. Maceió: Livraria Fonseca, 1904.

LEITE, Alcina Carolina. Campesinas. Maceió: Typ. de Amintas de Mendonça, 1889.

NEVES, Lúcia M. Bastos Pereira das (org.). Livros e impressos: retratos do Setecentos e do Oitocentos. Rio de Janeiro: EdUERJ, 2009.

ROMARIZ, Maria Lucia. Almanack Litterario Alagoano das Senhoras para 1889. Maceió: Typ. Novo-Mundo, 1889, ano II.

. "A primeira nuvem - ao festejado poeta pernambucano J. Duarte Filho". Novo Almanach de Lembranças Luso-brasileiro para o ano de 1888. Lisboa: Livraria Antonio Maria Pereira, 1887, pp. 132-4.

. Almanack Litterario Alagoano das Senhoras. Maceió: Typ. de Antonio

Luís \& Cia., 1888, ano I.

SCHUELER, Alessandra Frota M. de. "Professores primários como intelectuais da cidade: um estudo sobre produção escrita e sociabilidade intelectual (Corte Imperial, 1860-1889)". Revista de Educação Pública, n. 17, Universidade Federal do Mato Grosso, 2008. 